\title{
Teaching Cultural Competency through Global Health Education at Weill Cornell Medicine
}

Katharine-Grace Norris, ${ }^{1}$ Caitlin Noonan, ${ }^{2}$ Roger Ying, ${ }^{2}$ Claire T. Kenney, ${ }^{2}$ Jennifer Huang, ${ }^{2}$ Brienne Lubor, ${ }^{2}$ Rohini Kopparam, ${ }^{2}$ Elena Beideck, ${ }^{2}$ Priyanka Patel, ${ }^{2}$ Madelon L. Finkel. ${ }^{2}$

\begin{abstract}
Background: Educating medical students to better understand the complexities of cultural competence, the social determinants and environmental determinants of health that are important and integral components of the medical school curriculum. Methods: In 2014, Weill Cornell Medicine (WCM) implemented a new curriculum, the adoption of which provided the means to enhance an existing global health program, informally introduced in 2009, and to address the issues of cultural competency. In this article, we share WCM's experience in building and expanding its global health curriculum. Results: A hallmark of our program is the successful collaboration between students and faculty to create a multi-disciplinary global health program that incorporates electives, clinical field placement, and collaborative research. Conclusion: Key lessons learned through our experience include the necessity for strong faculty-student collaboration, full support from the administration, and building global partnerships. Our example could be a useful guide for other medical schools seeking to establish a global health education curriculum.
\end{abstract}

Key Words: Global health; Cultural competency (Source: MeSH-NLM).

\section{Introduction}

The Liaison Committee on Medical Education lists 'Cultural Competency and Health Care Disparities' as an important element in its 12 accreditation standards. Section 7.6 clearly states that the medical school curriculum should include "...opportunities for medical students to learn to recognize and appropriately address gender and cultural biases in themselves, in others, and in the health care delivery process." Educating medical students to better understand the complexities of cultural competence and the social and environmental determinants of health are viewed as integral components in the medical school curriculum..$^{2-3}$ Focusing on global health is also viewed as a means of addressing diversity and cultural competency. ${ }^{4-7}$ Within the past decade, many medical schools have introduced a global health component into their curricula, although the structure of which varies widely in scope and content. The most prevalent example of a global health program is offering an international elective experience. Between 1998 and 2008, medical schools in the United States and Canada experienced a $270 \%$ increase in the number of students participating in an international experience. ${ }^{8}$ As of 2013, the latest year for which we found available data, at least two-thirds of medical schools offered global health opportunities. ${ }^{2}$ However, little standardization across programs existed in terms of requirements for didactic, clinical, scholarly, and cultural components. ${ }^{10}$

There is no "right way" to present global health, and the scope and content of global health curricula vary among medical schools. Some schools have the capacity to organize and administer their own global health program, while others may have to rely on outside entities to do so. For example, the American Association of Medical Colleges (AAMC) Visiting Student Learning Opportunities (VSLO) program merged two existing visiting student programs: the Visiting Student Application Service (VSAS $®$ ) and the Global Health Learning 0pportunities (CHLO $®$ ). The VSLO program provides assistance to institutions located in the U.S. that either send their students to other U.S. medical schools or receive students from other U.S. medical schools. The Clobal Network component of the VSLO program assists institutions located in the U.S. and overseas to enable students to participate in an international elective at a host institution. ${ }^{11}$

In this article, we describe WCM's innovative and integrated approach to offering global health teaching in the medical school curriculum. A hallmark of our program is the successful collaboration between students and faculty who work together to create a multi-disciplinary global health program focused on education, clinical field placement, and collaborative research. Throughout all aspects of the program, cultural competency is an essential and valued component.

\section{Methods}

About the Weill Cornell Medicine Global Health Program

Global health opportunities, including applied experiences and research abroad, have been available to Weill Cornell Medicine (WCM) students since the 1970s. Over time, the scope and focus of the program greatly expanded from initial research and training sites in Haiti and Brazil, to partnerships with medical schools and hospitals across six continents. In 2004, the Office of Global Health Education (OGHE) was established by the Office of the Dean of the medical school to coordinate global health educational activities. The intent was to expand and enrich international opportunities available to WCM students and to foster partnerships with leading medical schools around the world. This engagement has led to collaborative research and bilateral educational opportunities. A previous article describes this early development of WCM's global health program. ${ }^{12}$

Despite the growth of the applied experience component of the global health program at WCM, there was no formalized curriculum for students to learn about global health. In 2009, a small group of WCM faculty members, the Clobal Health Teaching Associate, an

Medical Student, Rochester School of Medicine and Dentistry, NY, United States.
2 Joan \& Sanford I. Weill Medical College of Cornell University, NU, United States.

About the Author: Katharine-Grace Norris is a medical student at University of Rochester School of Medicine and Dentistry. Previously, she worked as the Global Health Teaching Associate in the Office of Global Health Education at Weill Cornell Medicine.

Correspondence:

Priyanka Patel

Address: 1300 York Ave, New York, NY 10065. USA.

Email: prp4004@med.cornell.edu
Editor: Mihnea-Alexandru Căman Associate Editors: Ammar Ismail Submission: Nov 5, 2019 Acceptance: Jan 24, 2020 Publication: Apr 30, 2020 Process: Peer-reviewed 
administrative assistant to the global health program, and medical students developed the Global Health Curriculum (GHC), which initially consisted of an informal collection of a global health activities, including applied experiences abroad and seminars. In order to create a formal global health course, we relied on the set of core competencies published by the Consortium of Universities for Global Health. ${ }^{13}$ An interdisciplinary curriculum for the formal global health course addressed five core competencies:

1. Global Burden of Disease

2. Health, Equity and Social Justice

3. Globalization of Health and Healthcare

4. Capacity Strengthening of Global Public Health Programs

5. Comparative Health Systems and Health Care Delivery

This initiative would not have succeeded without the full support and collaboration of faculty, students, and the administration.

\section{Results}

\section{Evolution and Change of the Global Health Curriculum}

In 2014, WCM, along with many other medical schools, adopted a revised medical school curriculum. At this time, almost all ( $98 \%)$ of U.S. medical schools enacted curricula changes that "enhanced integration of basic science content (e.g., an organ-system/case-based curriculum)" and $95 \%$ of U.S. medical schools made changes that "enhanced clinical correlations in the preclinical years." 14 At WCM, the new curriculum, among other things, increased emphasis on early clinical exposure during the first year, which allowed students to interact with patients beginning in the first semester of medical school. Issues relating to health care diversity are included in all modules. Curriculum revision also enabled the integration of global health into the four-year curriculum through the newly created Areas of Concentration $(A O C)$ curriculum course that also spans the four years of medical school.

The $A O C$ course mandates that students declare a research focus, and after the completion of the core clinical clerkships, conduct a dedicated six-month scholarly research project under the mentorship of a WCM faculty member. Global Health was approved as an AOC option for students. As such, it became imperative that the nascent GHC expand to meet the qualifications of the AOC program. What emerged was a robust multi-focused program that enabled global health to be incorporated into the medical school curriculum in a comprehensive way.

\section{Global Health Electives and Research Opportunities}

The global health program includes electives, seminars, and opportunities abroad that span the four years of medical school.

Courses and Electives: Introduction to Global Health, an elective offered in the second semester of the first year, focuses on a range of global health topics, including the global burden of disease, comparative health systems, infectious disease, and non-communicable diseases in low- and middle-income countries. Foundations in Global Service, an elective offered in the second semester of the first year, focuses on preparing students to conduct global health field work. This elective enables students to explore practical and ethical considerations before taking electives abroad. The Global Health Preceptorship is offered as an option in the required clinical preceptorship program during the first and second semesters of the first year. ${ }^{15}$ The global health clinical preceptorship was established to enable first-year students to participate in healthcare delivery to marginalized, resource-limited populations in New York City. Students are assigned to a clinic or physician's office located in under-served area of the city, and spend one afternoon each week shadowing physicians over a five-week period. Students also complete weekly readings to learn about the clinical and social approaches to working with vulnerable populations in New York City. These topics include, the social determinants of health, immigrant health, language discordance, and healthcare as a human right. To complete the course, students attend a critical reflection session which allows students to process and share their experiences with their peers.
Global Health Lecture and Seminar Series: Global Health Grand Rounds are scheduled several times during the academic year. Renowned global health leaders from around the world are invited to speak on timely global health topics. Global Health Career Seminars, scheduled monthly throughout the academic year, offer students the opportunity to have conversations with WCM clinical and research faculty who are engaged in global health work. These small group sessions $(\sim 25$ students) provide a more informal way for students to appreciate how global health can be incorporated into clinical medicine.

Applied Global Health Experiences: During the summer between the first and second years, WCM students can take an 8-week first-year international summer elective under the supervision of a host mentor. Projects typically focus on population/community health research, as students do not have sufficient clinical skills at this point of time in their medical school training. Students participate in an ongoing research project under the mentorship of the host researcher. of the approximately 100 students in each class, about 7-12 students take advantage of this opportunity, for which work-study funding is available $(\sim 3,000)$. During their final year of study, students are offered another opportunity to complete an applied global health experience, known as the fourth-year international elective. Approximately 35-40 percent of the fourth-year students take an international clinical elective, which ranges from four-to-eight weeks in length. The office of Global Health Education (OCHE) oversees these international clinical electives (see www.med.cornell.edu/international). Some programs focus solely on clinical care while others combine clinical care with learning more about the healthcare system of the host country.

Students receive a travel stipend $(\$ 3,000)$ from which airfare accommodations, and living expenses can be paid for. The stipend, allocated by OGHE to all students who take a clinical elective abroad, is funded by gifts, donations, and endowments made to OCHE by donors. A small percentage of students (1-3\%) take a research year off between the $3^{\text {rd }}$ and $4^{\text {th }}$ year to do global health research at a host institution. A small stipend $(\sim 1500)$ is also provided to help defray the cost of living. Many students also receive research grants (.i.e., NIH, Foundation funding) to help defray the costs of conducting research abroad.

AOC Research: An important component of the $A O C$ course is the Scholarly Project (SP). In second year, every student identifies an area of clinical research interest and prepares a research proposal that forms the basis of their SP. A WCM faculty member serves as the primary mentor who oversees the student's research, and the final, journalstyle written report is reviewed and approved by two independent $A O C$ faculty members. The project must be original research that is part of an existing grant-funded project or conceived by the student. Built into the curriculum is a dedicated six-month period during the third year in which the student is not taking any clinical rotations or electives. The block of time is specific to conducting research. The research may be conducted at Weill Cornell, at another medical school in the U.S., or abroad. A faculty mentor at Weill Cornell and a research mentor at the host institution are responsible for overseeing the student's work, and the WCM mentor has the responsibility of approving the finished product. All projects must have Institutional Review Board (IRB) approval from the institution at which the research is being done. Examples of past scholarly projects that focused on some aspect of global health include research in palliative care in India, hypertension in rural Tanzania, and multi-drug resistant TB in Sub-Saharan Africa.

Certificate in Global Health: To earn a Certificate in Global Health, an acknowledgment of active participation in the global health program at Weill Cornell, students must select global health as their primary or secondary AOC for their scholarly project. Additionally, students must be actively engaged in at least one global health program on campus (i.e., Global Health Grand Rounds, Global Health Career Seminars) and take at least one international elective abroad. The Certificates are awarded at a special event prior to graduation. Since the inception of the Certificate, approximately 15-25 students in each graduating class $(\mathrm{N}=100)$ have received the Certificate in Clobal Health. (Figure 1). 


\section{Criteria for a Certificate in Global Health}

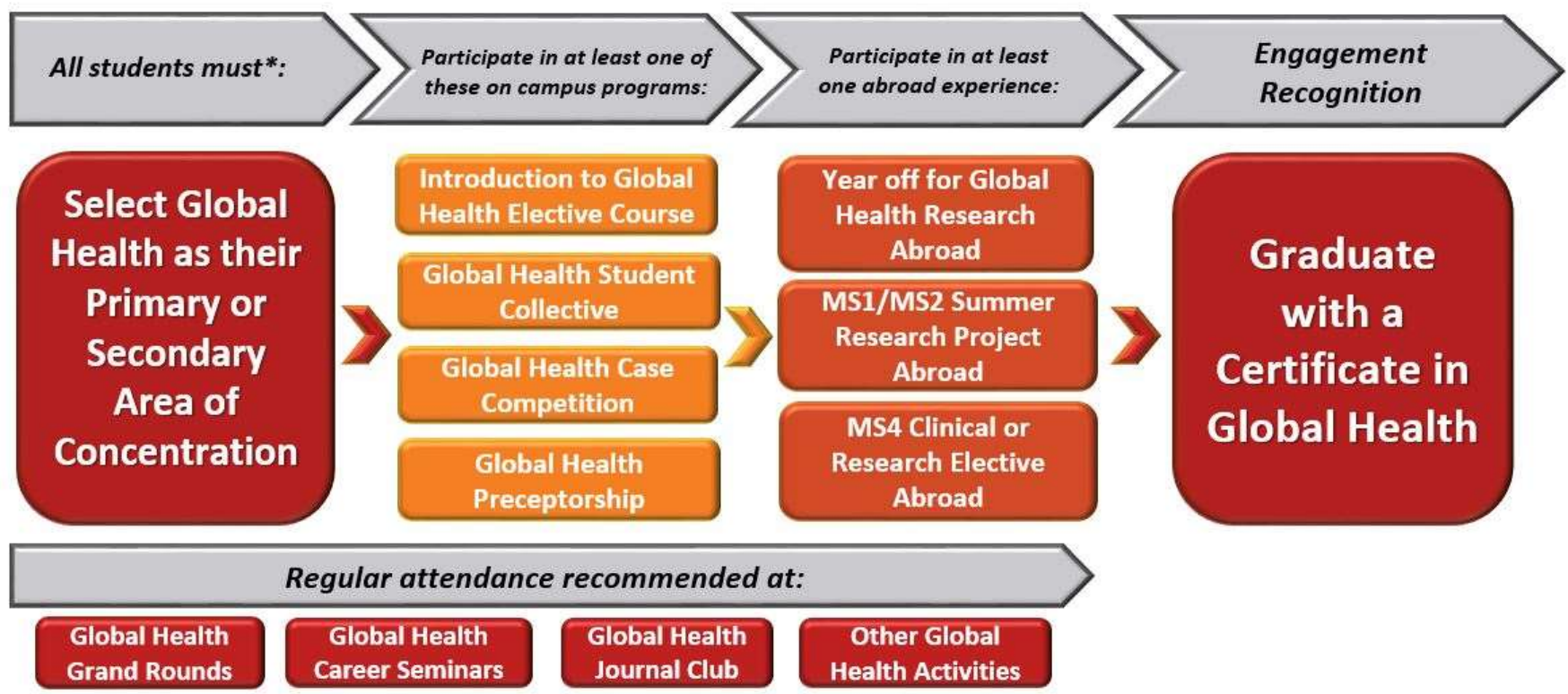

* For MD/PhD students there is no AOC selection requirement. Thus in order for MD/PhD student to qualify for the certificate, they must become a member of the Global Health Collective in lieu of selecting Global Health as their primary or secondary AOC.

Weill Cornell Medicine Global Health Education

\section{Faculty Involvement}

All global health programs and initiatives have faculty input. A multidisciplinary group of faculty throughout WCM, known as the Global Health Faculty Advisory Group, reviews all student applications requesting an international elective. If faculty approval is not given, the student is invited to revise and resubmit their proposal. For example, if the proposal does not clearly state what the student is planning to do during this elective, or if the host mentor is deemed inappropriate, the Advisory Group will request further information and clarification. Students whose proposals are ultimately not approved are ineligible to take part in the international elective and to receive funding. The Global Health Faculty Advisory Group also plans new curricular initiatives, establishes new international and local partnerships, and serves as student mentors. Their role is essential to the continued success of the program.

\section{Student-Led Initiatives}

OCHE has carefully fostered a global health community of interested students and faculty members. Student involvement is hugely important to the success of our global health program. The Global Health Teaching Associate, a full-time position in OCHE, serves as the bridge between students and faculty. The position is usually filled by a recent college graduate with strong global health experience. This individual also coordinates the global health courses and program activities.

A student group, the Global Health Collective, was formalized in 2014 to work collaboratively with the global health faculty in organizing lectures and seminars, as well as to give the students a voice in designing new global health initiatives. One of the main objectives of the Collective is to work with OGHE to foster a sense of community among students and faculty within the global health network at WCM. In an effort to achieve this goal, the Collective, in collaboration with OGHE, organizes various global health career seminars and student panels discussing experiences abroad. The global health career seminars, in particular, are very popular among the students. These informal, small group $(\mathrm{N}=25)$ sessions enable interested students to meet with faculty members who are engaged in global health activities as well as clinical care and to understand better how to integrate clinical medicine and global health into a career.

The Clobal Health Collective has also developed many student-led initiatives, such as the Global Health Journal Club, as a way for students to learn about new research in global health, as well as to have discussions on current global health topics. The Journal club is now organized as a monthly event in which a Weill Cornell student presents a scientific article and leads a discussion with the student audience on the topic.

The Infectious Disease (ID) Interest Group seeks to inform students about careers related to ID, connect them to ID faculty, and link them to research opportunities within the WCM community. The group disseminates information on ID research opportunities, organizes shadowing experiences, and convenes faculty panels so that students can learn about ID-related career opportunities, as well as meet potential mentors. It also organizes events surrounding World AIDS Day and other important global health events to increase student understanding and awareness of specific global health topics.

The Cornell Water Society offers students the opportunity to participate in a clean water project (i.e., installation of a solar-powered water pump and filtration system) in rural Shinyanga, Tanzania. This project is the result of an international collaboration of non-governmental organizations (NCOS)GOS, local community members, and WCM students. The Weill Cornell Water Society is currently conducting research to assess whether the water pump system has contributed to reduction in the incidence of diarrhea in children under five years of age. In doing so, students gain experience participating in international public health initiatives and research in a meaningful way.

The Center for Human Rights is a Weill Cornell Medicine faculty and medical student-run human rights clinic dedicated to providing forensic medical evaluations to individuals seeking asylum in the United States. The clinic is staffed by physician volunteers, and students are afforded first-hand experience in the assessment of human rights violations. 


\section{Strengthening Opportunities for Faculty Mentorship}

Building a roster of Clobal Health Faculty mentors was essential to the success of the program. These individuals guide interested students in finding projects and opportunities abroad, and connect them to mentors at the host institutions. OGHE has created a database of over 60 WCM faculty members and researchers who are involved in global health activities in over 28 countries. Additionally, OGHE hosts Social Hours between faculty members and students in order to facilitate networking and share updates on ongoing research projects. Prior to this, navigating the multitude of global health mentorship opportunities was cumbersome. The global health faculty database and Social Hours have improved the process of finding an appropriate global health mentor.

Communicating global health activities, updates, and new initiatives to the WCM community and general public is crucial for the efficien functioning of the program. OCHE's website has been restructured to provide students with current information and insight about various global health opportunities. Included is a robust set of student resources, including a Travel Handbook and a Global Health Student Guidebook that outline our programs and list all WCM faculty who are currently conducting global health research.

\section{Administrative Support and Funding}

Support for global health by the WCM Administration has been essential to the strength of our program. WCM leadership has been highly supportive of our initiatives and activities. While global health programs at other medical schools may receive their primary funding from their school administration, OGHE is self-funded thanks to the large number of endowments provided by generous donors as well as by elective fees charged to visiting international students who take clinical electives at WCM and its affiliated hospitals. We realize that our financial situation may be quite different from other schools and are grateful to our donors for their support of our programs.

\section{Discussion}

\section{Next Steps}

The WCM global health program continues to be a work in progressgrowing substantially over the past decade and continuing to learn how to navigate and overcome challenges that arise. Its integration into the medical school curriculum was a tremendous step in validating the importance of this area of study and its necessary place in the curriculum. After its integration, it was imperative that accessibility be expanded so that any student could participate regardless of financial constraints. Further, didactic coursework and applied experiences were expanded to expose students to an array of issues and topics, which serve to broaden and deepen the traditional medical school curriculum. Given the diverse educational, professional, and cultural backgrounds of students, and their different levels of exposure to global health topics, creating a learning environment that encompasses the global context enables students to develop the skills required of physicians in today's world. 


\section{References}

1. Functions and Structure of a Medical School: Standards for Accreditation of Medical Education Programs Leading to the MD Degree. Available from: http://lcme.org/publications/.

2. Kripalani S, Bussey-Jones J, Katz MG, Genao I. A prescription for cultural competence in medical education. J Gen Intern Med. 2006 0ct; 21(10): 1116-20.

3. Jernigan $\mathrm{V}$, Hearod JB, Tran $\mathrm{K}$, et al. An examination of cultural competence training in US medical education guided by the tool for assessing cultural competence training. J Health Dispar Res Pract. 2016 Fall; 9(3): 150-67.

4. Drain PK, Primack A, Hunt DD, Fawzi WW, Holmes KK, Gardner P. Global health in medical education: a call for more training and opportunities. Acad Med. 2007 Mar;82(3):226-30.

5. Houpt ER, Pearson RD, Hall TL. Three domains of competency in global health education: recommendations for all medical students. Acad Med. 2007 $\operatorname{Mar} ; 82(3): 222-25$.

6. Parisi V, Ahmed Z, Lardner D, Cho E. Global health simulations yield culturally competent medical providers. Medical Education. 2012 Nov; 46(11):1126-27.

7. Göpfert A, Mohamedbhai $\mathrm{H}$, Mise J, et al. Do medical students want to learn about global health? Glob Health Action. 2014 May;7:23943.

8. Brewer TF, Saba N, Clair V. From boutique to basic: A call for standardised medical education in global health. Med Educ. 2009 0ct;43:930-933.
9. Khan $O A$, Guerrant R, Sanders J, et al. Global health education in U.S. medical schools. BMC Med Educ. 2013 Jan;13:3. Published online 2013 Jan 18. doi: 10.1186/1472-6920-13-3.

10. Peluso MJ, Forrestel AK, Hafler JP, Rohrbaugh RM. Structured global health programs in U.S. medical schools: a web-based review of certificates, tracks, and concentrations. Acad Med. 2013 Jan; 88(1):124-30.

11. AAMC. Visiting Student Services. Available from: https://studentsresidents.aamc.org/attending-medical-school/article/about-vslo/.

12. Francis ER, Goodsmith N, Michelow M, et al. The global health curriculum of Weill Cornell Medical College: how one school developed a global health program. Acad Med. 2012 Sep;87(9):1296-1302.

13. CUGH Global Health Education Competencies Tool Kit. Available from: https://www.cugh.org/resources/2063.

14. AAMC. Curriculum Change in US Medical Schools: Implementation of Change in 2012- 2013. Available from: https://www.aamc.org/initiatives/cir/427196/27.html.

15. Kulkarni A, Francis ER, Clark T, et al. How we developed a locally focused Global Health Clinical Preceptorship at Weill Cornell Medical College. Medical teacher. 2014 Mar; 36(7): 573-577.

\section{Acknowledgments}

We want to thank Elizabeth R. Francis, MPH, a MD Candidate at Penn State College of Medicine, Anna Sophia McKenney, MD, PhD, MPH, and Margaret Fabizak, MD-PhD candidate at Weill Cornell Medicine for their leadership and passion in building the global health program at WCM. We also thank WCM global health faculty mentors, including Drs. Daniel Fitzgerald, Warren Johnson, Oliver Fein, and Satchit Balsari, who were instrumental in helping to build the WCM Global Health program.

\section{Conflict of Interest Statement at Funding}

The Authors have no funding, financial relationships or conflicts of interest to disclose.

\section{Author Contributions}

Conceptualization: KGN. Writing - Review \& Editing: KGN. Supervision: KGN. Project Administration: KGN. Conceptualization: CN. Formal Analysis: CN Resources: CN. Writing - Original Draft: CN. Project Administration: CN. Conceptualization: RY. Writing - Original Draft: RY. Methodology: RY. Writing - Review at Editing: RY. Conceptualization: CTK. Methodology: CTK. Data Curation: CTK. Investigation: CTK. Writing - Original Draft: CTK. Writing - Review A Editing: CTK. Project Administration: CTK. Project Administration: JH. Methodology: JH. Data Curation: JH. Conceptualization: BCL. Methodology: BCL. Data Curation: BCL. Investigation: BCL. Writing - Original Draft: BCL. Writing - Review đt Editing: BCL. Visualization: BCL. Conceptualization: RK. Formal Analysis: RK. Project Administration: RK. Methodology: RK. Data Curation: RK. Writing - Review A Editing: RK. Conceptualization: EB. Writing - Original Draft: EB. Writing - Review a Editing: EB. Project Administration: PP. Writing - Review \& Editing: PP. Conceptualization: MF. Writing- Review đt Editing: MF. Supervision: MF.

\section{Cite as:}

Norris KG, Noonan C, Ying R, Kenney CT, Huang J, Lubor B, et al. Teaching Cultural Competency through Global Health Education at Weill Cornell Medicine. Int J Med Students. 2020 Jan-Apr;8(1):15-19. 